\title{
An efficient method for considering the directionality effect of earthquakes on structures
}

Recent researches have proven the importance of considering the directionality effect on the expected seismic damage of structures. However, it demands a high computational effort if the nonlinear dynamic analysis (NLDA) is used to estimate the seismic response. This paper presents a simplified approach to obtain peak response parameters for a building subjected to ground motions considering the directionality effect. To do so, the maximum and median response spectra, considering all the non-redundant response spectra, of several ground motion pairs are calculated. Afterwards, a spectral matching technique is applied to these spectra and new acceleration components are obtained. A series of NLDA are performed with these new components and the roof displacement and base shear values are calculated. These results are compared with the maximum and median values, calculated by performing a series of NLDA, after rotating the earthquakes records by considering increments of $1^{\circ}$ in the interval $0^{\circ}-180^{\circ}$. The results agree with both approaches validating the efficiency of the simplified proposed approach.

Keywords: directionality; dynamic analysis; orientation-independent measures; spectral response; time-history

\section{Introduction}

When an earthquake occurs, the accelerations generated by the event are usually recorded in three orthogonal components corresponding to two horizontals and a vertical one. These three components represent the translational motion of the point where the sensor is located, but they do not necessarily allow capturing the maximum seismic demand of a structural system. It is because ground motions will depend on the position and orientation of the sensor with respect to a given reference system [Boore, WatsonLamprey and Abrahamson, 2006]. Consequently, for estimating the dynamic response of a structure is commonly recommended to find the angle producing the peak demand to be conservative [Athanatopoulou, 2005; Lucchini et al., 2011;Kostinakis et al., 2018]. 
Notice that, the predominant acceleration acting on a structure will also depend on its azimuthal orientation. This effect has been widely studied focusing on the expected performance and damage in structures and on the seismic hazard [Lagaros, 2010; Mackie et al., 2011; Nguyen and Kim, 2013; Torbol and Shinozuka, 2014; Bradley and Baker, 2015; Fontara et al, 2015; Vargas-Alzate et al., 2018; Pinzón et al., 2018a].

The present study is focused on the building performance variation induced by the directionality effect of earthquakes. At this respect, several methodologies to obtain the rotated ground motion record which generates the maximum response of the structure have been developed to date [Rigato and Medina, 2007; Cantagallo, Camata, and Spacone, 2012]. In these methodologies, the horizontal acceleration components of an earthquake are rotated, ranging from $0^{\circ}$ to $180^{\circ}$, for regular buildings and from $0^{\circ}$ to $360^{\circ}$, for irregular ones, generally considering increments of $1^{\circ}$. Then, 180 or 360 dynamic analyses should be performed, respectively. Once the dynamic analyses have been performed, one can obtain the seismic response for any percentile. However, such approach is computationally expensive. In order to reduce the high computational effort involved, a simplified method to predict the building response for any percentile is developed herein.

This method is based on the combination of two techniques widely used in the last decade namely the sensor-orientation-independent intensity measures (RotDpp IMs) proposed by Boore [2010] and the spectral matching technique, which is summarized in section 2.2.1. To simplify the implementation of the simplified method, an application named MatchPercentile has been developed. This app is useful to obtain new ground motion pairs which are consistent with any demand percentile by considering the sensororientation-independent intensity measures mentioned above. 
The simplified presented approach is tested against the more computational effort method, through the nonlinear dynamic analysis (NLDA), in order to demonstrate its advantages. To do so, a regular 4-story steel building and a L-shape irregular 4-story steel building, both with a structural system of special moment frames (SMF), modeled with Ruaumoko 3D software [Carr, 2002], have been developed. A total of 20 ground motion pairs recorded in Italy were used as seismic input. The results obtained with both approaches were compared and similar results have been obtained.

\section{Methodology}

In this section are presented two methods to evaluate the behavior of a building by considering the effect of the seismic directionality. The first method is the most commonly used when the directionality effect is evaluated over a structure and will be named 'complete rotational method', CRM. In this method, a series of NLDA should be performed with the rotated ground motions, by considering increments of $1^{\circ}$, until reaching $180^{\circ}$. Thus, a total of 180 dynamic analyses per ground motion pair should be performed. In this way, a distribution of any output variable can be obtained allowing to estimate any percentile level. The second method will be named 'predictive percentile method', PPM. This method seeks to predict any percentile level of an output variable, from a new pair of ground motions which has been adjusted by considering the RotDpp IM and the spectral matching technique. This efficient approach will significantly reduce the computational effort as will be shown below.

\subsection{Complete rotational method}

Some recent researches have shown that the maximum ductility demand of an elastoplastic single-degree-of-freedom system could occur at a different angle from the as-recorded one [Garcia-Soto, Hong, and Gómez, 2012]. Similar conclusions have been 
observed when estimating the maximum displacement response and maximum expected damage of 3D multi-degree-of-freedom building models [Kostinakis et al., 2015; Kostinakis et al., 2018; Vargas-Alzate et al., 2018]. To analyze this effect for a particular building and earthquake, by considering the CRM, the following steps should be achieved:

(1) A 3D model of the building should be created.

(2) The horizontal components of the earthquake are rotated to the first considered angle. Notice that, the first calculation will be performed for the as-recorded components, i.e. $\theta=0$ (see equation 1$)$.

(3) A NLDA is computed for the rotated components.

(4) Steps 2 and 3 are repeated with increments of $1^{\circ}$ in the range of $0^{\circ}$ to $180^{\circ}$. Depending on the structural irregularity, the analysis should be performed to $360^{\circ}$.

The rotated horizontal components, $\operatorname{accx}(\theta)$ and $\operatorname{accy}(\theta)$, are obtained by using linear combinations of the as-recorded components (accx and accy) as a function of the rotational angle $(\theta)$, through the following equation [Boore et al., 2006]:

$$
\begin{aligned}
& \operatorname{accx}(\theta) \\
& \operatorname{accy}(\theta)
\end{aligned}=\left[\begin{array}{cc}
\cos (\theta) & \sin (\theta) \\
-\sin (\theta) & \cos (\theta)
\end{array}\right] *\left[\begin{array}{l}
\operatorname{acc}_{\mathrm{X}} \\
\operatorname{acc}_{\mathrm{Y}}
\end{array}\right] \quad \theta=0^{\circ}, 1^{\mathrm{o}}, \ldots \mathrm{N}^{\mathrm{o}}
$$

where $\mathrm{N}$ represents the maximum angle considered.

In order to illustrate how much can vary the spectral ordinates of an earthquake as a function of the rotational angle, Fig. 1 shows the 180 response spectra calculated for each one of the rotated components of the earthquake of Umbria (see earthquake \#2 in Table 2). In this figure is also illustrated the RotD100 and the RotD50, which are intensity measures related to the maximum and median spectrum, respectively. It is important to mention that the calculation time induced by the rotational analysis of the signal can be 
reduced if the linear combination of equation (1) is performed by using the oscillator time series responses instead of the as-recorded acceleration components.

As a result of the directionality analysis based on CRM, it can be obtained relationships between several output variables such as the roof displacement $(\delta)$ and the base shear $\left(V_{B}\right)$ as a function of the rotation angle $(\theta)$. However, the high computational cost of performing hundreds of NLDA makes difficult to include the directionality effect. For this reason, it would be of practice interest to develop a simplified methodology allowing to obtain similar results to those based on the CRM, but with a fraction of the computational effort.

\subsection{Predictive percentile method}

As mentioned above, the aim of the PPM is to reduce the high computational cost involved when applying the CRM. PPM is based on the spectral matching technique in combination with the sensor-orientation-independent intensity measure, RotDpp [Boore, 2010]. The intrinsic logic of this simplified method is that one can predict the maximum response of a structure to a given rotated ground motion, if the frequency content of the pair of horizontal records is modified to fit the response spectra related to the RotD100. In a general sense, one can predict the response of the structure to any percentile (pp), only by adjusting the frequency content of the earthquake record, in such a way that the spectra of the ground motions are compatible with the response spectra of the desired demand percentile. In this way, the computational time can be highly reduced since only two NLDA should be performed. Notice that in the case of the RotD100 the calculation can be simplified using the Root-sum-of-squares $(R S S)$ or the vector composition ( $m p V C)$ measures [Pinzón et al., 2018b].

To apply the PPM for a particular building and for a specific ground motion pair 
the following steps should be considered:

(1) As in the CRM, a 3D model of the structure should be created.

(2) Case 1. If the aim is to find the maximum response, the RSS spectrum must be computed. This spectrum represents the maximum spectral response for all the oscillator periods of the rotated ground motions used as input.

Case 2. If the response for a specific percentile wants to be found, the RotDpp spectrum for the percentile pp should be estimated.

(3) Spectral matching. The response spectrum defined in the previous step is used as a target spectrum and, by using a spectral matching method [Atik and Abrahamson, 2010; Hancock et al., 2006; Jayaram et al., 2011], two new ground motions compatible with the target spectrum are obtained $(\mathrm{N}-\mathrm{S}$ matched and E-W matched). In this study, the spectral matching technique applied is described in section 2.2.1.

(4) Dynamic analyses. The new pair of ground motions is applied in the main directions of the building. Two NLDA are performed alternating the accelerograms in each direction of the building (see Fig. 2). NLDA 1. N-S matched ground motion component applied in the $\mathrm{X}$ axis of the building and the E-W matched acceleration component applied in the $\mathrm{Y}$ axis of the building (Fig. 2a). NLDA 2. E-W matched ground motion component applied in the $\mathrm{X}$ axis of the building and the N-S matched acceleration component applied in the $\mathrm{Y}$ axis of the building (Fig. 2b).

To facilitate the implementation of the proposed simplified method, one application named MatchPercentile has been developed by using the commercial software MATLAB [MathWorks, 2017] (see Fig. 3). The users of the created software neither need to be proficient users of MATLAB nor to have the software installed. It is 
because the created program is a stand-alone version in .exe format and it works with Windows OS. MatchPercentile is useful to find ground motions compatibles with the response spectrum for a specific percentile depending on the angle to which the ground motion is rotated. As input parameters, it is required to enter the two acceleration horizontal components, the critical damping for the calculation of the response spectrum, the interval period of the spectrum, the expected demand to the desired percentile and the number of iterations allowing a better fitting of the target spectrum (a minimum of 10 iterations is recommended). The two acceleration components are obtained by using the equation (1), with increments of $1^{\circ}$, in the range between 0 and $180^{\circ}$. For each component of the earthquake record, the response spectrum is estimated. When the 180 spectra are obtained, the spectral values of all the rotational angles are sorted for each oscillator period. In this way, the $\mathrm{pp}^{\text {th }}$ percentile of the ground motion can be obtained. Once the response spectrum for a specific percentile is obtained, it becomes the target spectrum. Afterwards, the spectral matching technique is applied to the as-recorded ground motions in such a way to fit the target spectrum (see section 2.2.1.). In this way, two new horizontal components are obtained which can be used to perform the NLDA. It is expected that the results obtained with this approach fit quite well those obtained with the CRM.

\subsubsection{Spectral matching technique}

The increasing capabilities of modern computers have increased the importance and usefulness of dynamic analyses both for designing new structures and for assessing the expected performance of existing ones. Therefore, the availability of accelerograms fulfilling specific requirements is an issue of broad interest, especially when design or assessment are tackled from a probabilistic point of view. For this purpose, the spectral matching technique properly modifies the Fourier amplitude spectrum of a seed 
accelerogram so that the response spectrum is compatible with a predefined target spectrum, usually a code, prescribed or recommended, design spectrum.

Given an actual accelerogram, the key of the spectral matching method entails modifying its Fourier amplitude spectrum so that the response spectrum coincides with a target one. In an ideal world and for undamped systems, replacing the Fourier spectrum amplitudes by the target undamped velocity response spectrum would lead to a reasonable estimate of the solution of the problem. In practice and for any response spectrum, spectral matching involves an iterative process. This iterative process is necessary due to the nonlinearity of the response.

This iterative process may be applied to adjust acceleration, as well as velocity and displacement response spectra whichever the damping be since each iteration adequately modifies the Fourier spectrum according to the target spectrum. Thus, the spectral matching is done according to the following steps: Step 1) substitute the Fourier amplitude spectrum by the target spectrum; Step 2) calculation of the response spectrum $S R$, of the accelerogram; Step 3) a Factor function $F_{j k}$ is defined as follows:

$$
F_{j k}=\frac{S R_{\mathrm{obj}}}{S R_{j k}} \quad\left\{\begin{array}{l}
j=1 \cdots \mathrm{N}_{\text {freq }} \\
k=1 \cdots \mathrm{N}_{\text {Iter }}
\end{array}\right.
$$

subscript $j$ refers to the $j^{\text {th }}$ coordinate of both target spectrum $\left(S R_{o b j}\right)$ and response spectrum $(S R)$; the subscript $k$ refers to the $k^{\text {th }}$ iteration; Step 4$)$ a new accelerogram is defined by multiplying the Fourier amplitude spectrum by the factor $F_{j k}$; the inverse FFT provides the new accelerogram; Step 5): error analysis to end the iterative process or, eventually, to go back to Step 2. The iterative process may be concluded when an error criterion is fulfilled or a maximum number of iterations is met. It must be noted that Step 1) is optional and can be omitted; sometimes Step 1 speeds up the convergence of the 
iteration process, but the improvement of the final result of the spectral matching is not guaranteed. There are two crucial numerical aspects of accomplishing Step 3: i) modifying the Fourier spectrum should be done carefully and adequately. The Fast Fourier Transform (FFT) defines N FFT samples; the first N/2 correspond to positive frequencies between zero and the Nyquist frequency the rest of samples correspond to negative frequencies. The way for assigning the factor $F_{j k}$ of equation (2) is through a new function $\Theta_{i k}$ defined as follows:

$$
\Theta_{i k}=F_{j k} \quad \begin{cases}i=1 & j=\frac{N}{2} ; \\ i=2, \cdots, \frac{N}{2}+1 & j=1 \cdots \frac{N}{2} ; \\ i=\frac{N}{2}+2, \cdots, N & j=N+1-i ;\end{cases}
$$

where $N$ is the number of points of the accelerogram. Note that $N / 2$, in equation (3), is equal to $\mathrm{N}_{\text {freq }}$ in equation (2). Thus, once the function $\Theta_{i k}$ is defined it suffices to multiply the amplitude of the Fourier transform by $\Theta_{i k}$. ii) Simply because of round-off errors the modified Fourier transform may not be conjugate symmetric; that is $X(-\omega) \neq X^{*}(\omega)$. This feature should be carefully controlled in the computing platform used; MATLAB [MathWorks, 2017] allows the symmetric option for the inverse FFT to ensure that the inverse transform is a real function.

\section{Building's application model}

Two 4-story steel buildings are analysed in this paper; namely regular (rectangular shape in plan, Fig. 4) and irregular (L-shape in plan, Fig. 5) buildings, with Special Moment Frames (SMF). Steel W type sections (wide flange American section) are used for beams and columns, which are joined by means of prequalified connections [ANSI/AISC 358, 
2010] of Fully Restrained (FR) type. The buildings were designed for office use based on the provisions given in the AISC-341-10 [2010].

Both buildings have column sections type W16x89 and beam sections type W14X68 according to the ASTM A992. The buckling in columns was controlled in the design. The design of the SMFs satisfies the AISC criterion "strong- column-weakbeam" and the structural sections of the columns meet the slenderness criterion presented in AISC-341-10 [2010].

The NLDAs are performed with Ruaumoko 3D software [Carr, 2002]. The weight of the structure, as well as that of the architectural finishes and facilities, were considered as dead loads (DL), while the live loads values (LL) were selected according to ASCE 710 [2010] provisions for office use. Notice that beams and columns were modelled as frame type members, with plastic hinges at their ends. Plastic hinges follow the Bi-Linear Hysteresis rule with hardening and strength reduction based on the ductility factor [Carr, 2002]. Moreover, the values of strength and ductility for the hysteresis rule were calculated according to the modified Ibarra-Medina-Krawinkler (IMK) model [Ibarra et al., 2005; Lignos and Krawinkler, 2011, 2013; Diaz et al., 2017].

The interaction force between the two horizontal directions is considered in the nonlinear structural model. To do so, regarding the restoring stiffness forces, the interaction between the element forces in both horizontal directions is considered through the interaction yielding surface proposed by Chen and Atsuta [1976] for columns type section $\mathrm{W}$, which is given by the following equation:

$$
\frac{\left(\frac{M_{z}}{M Y_{z}}\right)^{\alpha}}{1.0-\left(\frac{P}{P_{y}}\right)^{\beta}}+\frac{M_{y}}{M Y_{y}}+\left(\frac{P}{P_{y}}\right)^{\gamma}=1.0
$$


where $\mathrm{P}_{\mathrm{y}}$ is the axial yielding load; $M Y_{z}$ and $M Y_{y}$ are the bending yielding moments about the $\mathrm{Z}$ and $\mathrm{Y}$ axes of the structural section; $P, M z$ and $M y$ are the acting axial load and bending moments about the $\mathrm{Z}$ and $\mathrm{Y}$ axes; $\alpha, \beta$ and $\gamma$ are the interaction terms defining the yielding surface in the transition between principal axes.

P-Delta effects have been considered in all the simulations to take into account the global stability of the structure. The panel zones were modelled by the rotational stiffness in the connections according to the model proposed by Krawinkler [1978] and presented in FEMA 355C [2000]. In all cases, as recommended for steel structures, for the first and last vibration mode under consideration [SAC, 1996], a value of $2 \%$ of damping was considered; the Rayleigh damping model was used in all the calculations. The main modal properties of the buildings are summarized in Tables 1 and 2 .

\section{Ground motions selection}

A ground motion selection process has been made with the aim of obtaining a group of records with diverse characteristics. The Italian accelerometric archive (ITACA) ${ }^{1}$ [Luzi et al., 2017] has been considered for this purpose. A total of 20 ground motions pairs (GMP) recorded in Italy were used according to the following conditions: a) Site conditions A (2 GMP), B (6 GMP), C (10 GMP) and E (2 GMP), following the Eurocode 8 specifications; b) Earthquakes Type 1 (11 GMP) and 2 (9 GMP), following the Eurocode 8 specifications; c) Peak ground acceleration (PGA) $\geq 0.05$ g; d) Depth $\leq 10$ $\mathrm{km}$. Table 3 shows the 20 ground motion pairs selected and their principal characteristics.

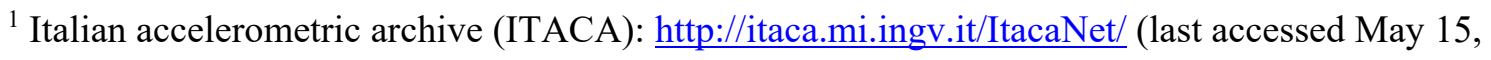
2017) 
Fig. 6 shows the particle acceleration motions of the 20 ground motion pairs selected. In this figure, different cases of polarization can be observed. Notice that most of them exhibit circularly motions. There are some cases as, for instance, ground motions 7, 17 and 18, in which a more linearly polarized behavior can be detected. Moreover, for the 20 ground motions, the maximum acceleration is also highlighted in this figure and it can be appreciated that it occurs for a different angle respect to the as-recorded one.

\section{Results}

The NLDA results obtained after performing the CRM and the PPM, which have been found after analyzing both regular and irregular 4-story SMF 3D models, with the 20 pairs of ground motion presented in Table 3, are presented in this section.

\subsection{Regular building}

To prove the effectiveness of the PPM, the Umbrian earthquake of October 30, 2016, recorded at T1220 station, was used as example. This earthquake registered a PGA of $0.26 \mathrm{~g}$ in the N-S component and $0.24 \mathrm{~g}$ in the E-W. In Fig. 7 the horizontal acceleration records of the described earthquake are shown.

Firstly, these as-recorded components were used to compute the CRM in the regular building. Therefore, 180 NLDA were performed and the roof displacement and the base shear were calculated for each rotational angle. Figs. 8 and 9 show the results obtained based on this method. The angle producing the maximum roof displacement in the X-Direction is $175^{\circ}$ and in the Y-Direction is $103^{\circ}$ (see Fig. 8). The base shear is maximum in the X-Direction for an angle equal to $5^{\circ}$ and in the Y-Direction for an angle equal to $110^{\circ}$ (see Fig. 9). It is important to mention that the plastic hinges occurring in the structure generally appear at the ends of the beams. Notice that this location varies 
from record-to-record and depend on the rotational angle.

For the PPM, the horizontal as-recorded components of acceleration were used as input for the MatchPercentile application. The analysis was performed with a damping ratio equal to $2 \%$; this value is recommended for steel frame buildings (Paz and Leigh, 2003). In Fig. 10, the RotD100 (Max RotD100), RotD50 (MedianRotD50) and the as-recorded components spectra are compared. The spectra corresponding to RotD100 and RotD50, become target spectra and the as-recorded ground motions are adjusted accordingly. Once adjusted, two new ground motions are generated, whose response spectra are RotD100 and RotD50, respectively. The new acceleration components are compared to the original ones in Fig. 11.

The matched accelerograms N-S Max.RotD100 and E-W Max.RotD100 are used as input to perform the NLDA and to estimate the maximum expected demand. The N-S Median.RotD50 and E-W Median.RotD50 are also used as input to estimate the median demand. After the NLDAs are performed, for the two cases mentioned above, two demand values were obtained for each direction. These values represent the maximum and the median response of the building. Fig. 12 and Fig. 13 show the comparison between the results obtained with the CRM and PPM, respectively.

The results obtained with the proposed method show a good agreement with the maximum and median values obtained with the CRM (Fig. 14). Regarding the maximum roof displacement, in the X-Direction, a value of $17.40 \mathrm{~cm}$ was obtained with CRM and $17.83 \mathrm{~cm}$ with PPM; in the Y-Direction, the values obtained are 6.89 and $7.23 \mathrm{~cm}$, respectively. The difference between these values is approximately $2 \%$ for the $\mathrm{X}$ Direction and 5\% for the Y-direction. In the case of the median roof displacement values, in the X-Direction, a value of $16.25 \mathrm{~cm}$ was obtained with CRM and $16.10 \mathrm{~cm}$ with PPM; 
in the Y-Direction values of $5.00 \mathrm{~cm}$ and $5.15 \mathrm{~cm}$ were obtained, respectively. Differences of 1\% (X-Direction) and 3\% (Y-Direction) were obtained. Regarding the maximum base shear, in the X-Direction, a value of $7587 \mathrm{kN}$ was achieved with the CRM and $7770 \mathrm{kN}$ with the PPM; in the Y-Direction values of $2397 \mathrm{kN}$ and $2513 \mathrm{kN}$ were obtained, respectively. Such results represent differences of $2 \%$ in the X-Direction and $5 \%$ in the Y-Direction. Finally, comparing the median base shear with the CRM, values of $7282 \mathrm{kN}$ and $1858 \mathrm{kN}$ were obtained for the $\mathrm{X}$ and $\mathrm{Y}$ directions, respectively. With PRM, values of $7267 \mathrm{kN}$ and $1829 \mathrm{kN}$ were obtained for the $\mathrm{X}$ and $\mathrm{Y}$ directions, respectively. These results represent differences of less than $1 \%$ in the X-Direction and $1.5 \%$ in the Y-Direction. In general, the differences obtained with the 20 GMP are in average of $4 \%$ for the roof displacement and 5\% for the base shear values. A summary of the results obtained for the 20 GMP pairs can be seen in Tables A.1, A.2, A.3 and A.4.

\subsection{Irregular building NLDA}

In the same way as the regular building, the as-recorded components, and the matched accelerograms N-S Max.RotD100 and E-W Max.RotD100, were used to compute the CRM and the PPM in the irregular one, respectively. Instead of 180 NLDA, 360 were performed with the CRM, due to the irregularity of the building. The roof displacement and the base shear were also estimated for each rotational angle. The maximum values obtained with the CRM were compared with the obtained ones using the PPM. As an example, Fig. 15 shows the results obtained with the ground motions of the Umbrian earthquake occurred on October 30, 2016, and recorded at T1220 station.

The maximum roof displacement, in the X-Direction, registered a value of 16.89 cm was obtained with CRM and $16.15 \mathrm{~cm}$ with PPM; in the Y-Direction, the values obtained are 6.47 and $6.76 \mathrm{~cm}$, respectively. The difference between these values is approximately $4 \%$ for the X-Direction and 5\% for the Y-direction. The difference 
increases $2 \%$ in the X-direction compared to the regular building analysis. In the case of the median values of roof displacement, in the X-Direction, a value of $15.29 \mathrm{~cm}$ was obtained with CRM and $15.56 \mathrm{~cm}$ with PPM; in the Y-Direction values of $5.04 \mathrm{~cm}$ and $5.15 \mathrm{~cm}$ were obtained, respectively. Differences of $2 \%$ in both directions were obtained. Similar results were obtained with the regular building.

Regarding the maximum base shear, in the X-Direction, a value of $10260 \mathrm{kN}$ was achieved with the CRM and $9869 \mathrm{kN}$ with the PPM; in the Y-Direction values of 3140 $\mathrm{kN}$ and $3018 \mathrm{kN}$ were obtained, respectively. These results represent differences of $4 \%$ in the X-Direction and 4\% in the Y-Direction. Finally, comparing the median base shear with the CRM, values of $9443 \mathrm{kN}$ and $2346 \mathrm{kN}$ were obtained for the $\mathrm{X}$ and $\mathrm{Y}$ directions, respectively. With PPM, values of $9317 \mathrm{kN}$ and $2338 \mathrm{kN}$ were obtained for the $\mathrm{X}$ and $\mathrm{Y}$ directions, respectively. These results represent differences of $1 \%$ in both directions. Similar results were obtained with the regular building.

In general, the differences obtained with the $20 \mathrm{GMP}$ are in average of $4 \%$ for the roof displacement and $6 \%$ for the base shear values, almost the same as the regular building. A summary of the results obtained for the 20 GMP can be seen in Tables A.5, A.6, A.7 and A.8.

\subsection{Performance in the non-linear range}

To evaluate the performance of the buildings and to validate the PPM approach in the non-linear range, the analyses have been performed with scaled ground motions. To ensure that the buildings are in the non-linear range, the 20 GMP from Table 3 were scaled to achieve a damage index between 0.2 and 0.5 in each structure [Diaz et al., 2017]. The results obtained after performing the CRM and the PPM for the maximum values can be seen in Tables 4 and 5 for the regular building and Tables 6 and 7 for the irregular one. 
The results obtained with the proposed method are very close to those obtained through the CRM. Regarding the maximum roof displacement, in the X-Direction, differences of $4 \%$ and 3\% (in average) were obtained for the regular and irregular buildings, respectively, when comparing the CRM and PPM results. In the Y-Direction, the differences are $4 \%$ and $5 \%$ for the regular and irregular, respectively. Comparing the maximum base shear obtained with the CRM and PPM, in the X-Direction, differences of 3\% (in average) for both, regular and irregular building, were found. Finally, for the Y-Direction, differences of $4 \%$ and $3 \%$ in the maximum base shear were obtained for the regular and irregular buildings, when comparing the results of both methods.

\subsection{Near- and far-fault earthquakes}

Near-fault earthquakes ground motion records are very different compare to far-fault ground motions. Near-fault records are characterized by having a long-period pulse in the velocity time history of the normal-fault component due to the directivity effect of these kind of events [Chopra and Chintanapakdee, 2001]. In Fig 16, the ground motion timehistories of the earthquake of Abruzzo and Lazio (2017) recorded in the MSCT station are shown as an example of a near-fault earthquake (GMP \#15 from Table 3). A clear pulse can be observed in the histories of velocities and displacements. In addition, Fig. 17 displays the 5\% damped elastic response spectra in acceleration, velocity and displacement for the same GMP. Another characteristic of the near-fault earthquakes' records is that the response spectra of the horizontal components are very different [Chopra and Chintanapakdee, 2001]. The impulsive characteristic of these earthquakes has attracted the attention of researchers when assessing the seismic response of a structure.

For this reason, the 20 GMP used in this study have been grouped according to their proximity to the fault. The objective is to validate the PPM for both types of records, 
near and far-fault, by analyzing the results independently. Table 8 present the hypocentral distance, peak ground acceleration (PGA), peak ground velocity (PGV), peak ground displacement (PGD) and fault proximity (NF: near-fault and FF: far-fault) for the 20 GMP. The selection has been made according to the study of Chopra and Chintanapakdee [2001]. A total of 10 near-fault and 10 far-fault earthquakes were obtained after the characterization.

Notice that the average error in percentage (\%, 1-CRM/PPM) found after comparing the maximum values of roof displacement and base shear by considering the non-scaled and scaled GMP, for the regular and irregular buildings, are compared in Table 9. The results indicate that the average error in near-fault events are relatively higher in most cases, with exception of the non-scaled analysis for the irregular building where similar errors were observed.

\section{Discussion and conclusions}

Recent research has shown the importance of considering the directionality effect when estimating the seismic response of structures. It has been demonstrated that the structural response strongly varies depending on the orientation of the structure with respect to the seismic action. For instance, Vargas-Alzate et al. [2018] and Pinzón et al. [2018a] demonstrated how buildings with very similar structural system and dimensions, located very close to each other, had different damage states depending on their orientation respect to the earthquake source.

As can be seen in this study, neglecting the directionality effect could underestimate the actual demand about $30 \%$, in some cases (see results of ground motion \#1 in Tables A1 to A8). This fact reaffirms the importance of considering the directionality effect in the structural analysis. Moreover, it should be regarded in 
structural seismic codes since it allows to improve the evaluation of the expected seismic damage in structures. For instance, for special facilities such as nuclear plants, hospitals, schools and other facilities that need to be operating after an earthquake, the RotD100 matched accelerograms should be used to estimate the seismic demand. Therefore, it will be guaranteed that the maximum seismic demand will be considered in the structural analysis.

The predictive percentile method provides a simplified alternative to obtain any percentile response without the need of performing hundreds of NLDA; this represents a decrease from 180 , if the increment for rotating the records is $1^{\circ}$, to only two NLDA. It is important to note that the PPM is useful to obtain a very good estimation of the variables analyzed when compared to the CRM, but this value do not always overestimate the one obtained with the CRM. For instance, note that in Table A1 the roof displacement under ground motion No 8 and 18 are underestimated by using PPM. The same occurs in Table A2 in which the PPM leads to an underestimation of the roof displacement under ground motion No 5. Moreover, the values presented in Tables 4-7 confirm that the estimation of the engineering demand parameters are randomly lower and higher than the one obtained with the CRM. However, as it has been mentioned above, the values obtained with the PPM are very close to the ones obtained through the CRM. Noteworthy, the differences in average are less than 5\% when applying the PPM.

Notice that the simplified method could be easily extended to improve seismic structural codes when considering non-scaled ground motions in the NLDA. In this respect, many authors have reported increments of about $10 \%$ when estimating the RotD100 to their matched spectra, using spectrally matched ground motions instead of scaled or as-recorded ones [Carballo, 2000; Seifried, 2013; Baker et al., 2015]. This increment agrees with the obtained ones in this research when the peak parameters of the 
as-recorded values are compared with the maximum values; differences are $10 \%$ in average. At this respect, the analysis of 949 response spectra, corresponding to the ground motion pairs from the ITACA database, was performed with the aim of finding the average ratio between the RotD100 to the larger of the two response spectra of the asrecorded horizontal components (Larger IM). Once the 949 ratios were calculated, the geometric mean is estimated in order to obtain a single ratio. The geometric mean was used since it is a more natural estimator compared to the arithmetic mean [Shahi and Baker, 2014]. The results show that the ratios are around 9\% (see Fig. 18). This proves why the simplified method works since the ratio between these two intensity measures remain, in average, when the roof displacement and the base shear values are calculated by using the PPM.

Summarizing, the simplified method, PPM, provides satisfactory results when are compared to those obtained by using the complete rotational method, CRM, for the two buildings analyzed herein. It is worth to mention that this method cannot be generalized based on the results of this study. This approach should be proved with different structural typologies, building shapes, heights, among other properties that vary the dynamic behavior. Nonetheless, this simplified method has proven to be so far an efficient and simple alternative to include the directionality effect on the seismic performance of buildings. To implement the PPM, the application developed herein named MatchPercentile will be of interest, since it provides a friendly computational environment to calculate the new pair of ground motion records allowing estimating any percentile structural response. This software is a free distribution application compatible with Windows OS and it is available online in the following website: https://deca.upc.edu/en/projects/Earthquake_Engineering/matchpercentile. 


\section{Acknowledgements}

This research was partially funded by the Spanish Government's Ministry of Economy and Competitiveness (MINECO) and by the European Regional Development Fund (ERDF) of the European Union (EU) through the project referenced as CGL2015-65913-P (MINECO/ERDF, EU). The first author is supported by a Ph.D. scholarship grant from the Institute for the Training and Development of Human Resources (IFARHU) and the Government of Panama's National Secretariat of Science, Technology, and Innovation (SENACYT).

\section{Appendix A}

The results obtained for the 20 non-scaled dynamic analyses are shown in tables A.1, A.2, A.3, A.4, A.5, A.6, A.7 and A.8.

\section{References}

AISC 341-10 [2010] "Seismic provisions for structural steel buildings," American Institute of Steel Construction, Chicago.

American Society of Civil Engineers (ASCE) [2010] "Minimum Design Loads for Buildings and Other Structures," ASCE/SEI 7-10, American Society of Civil Engineers/Structural Engineering Institute, Reston, Virginia.

ANSI/AISC 358 [2010] "Prequalified connections for special and intermediate steel moment frames for seismic applications," American Institute of Steel Construction, Chicago, $178 \mathrm{p}$.

ASTM A992 [2015] "Standard Specification for Structural Steel Shapes," ASTM International, West Conshohocken, PA.

Athanatopoulou, A. M. [2005] "Critical orientation of three correlated seismic components," Engineering Structures, 27(2), 301-312. doi: 10.1016/j.engstruct.2004.10.011

Atik, L. Al. and Abrahamson, N. A. [2010] "An improved method for nonstationary spectral matching," Earthquake Spectra, 26(3), 601-617. doi: $10.1193 / 1.3459159$

Baker, J. W., Haselton, C. B., Luco, N., Stewart, J. P. and Zimmerman, R. B. [2015] "Updated ground motion spectral matching requirements in the 2015 NEHRP Recommended Seismic Provisions," Proc. of the 6th International Conferences on Earthquake Geotechnical Engineering, Christchurch, New Zealand. 
Boore, D. M. [2010] "Orientation-Independent, Nongeometric-Mean Measures of Seismic Intensity from Two Horizontal Components of Motion," Bulletin of the Seismological Society of America, 100(4), 1830-1835. doi: $10.1785 / 0120090400$

Boore, D. M., Watson-Lamprey, J. A. and Abrahamson, N. A. [2006] "Orientationindependent measures of ground motion," Bulletin of the Seismological Society of America, 96(4A), 1502-1511. doi: 10.1785/0120050209

Bradley, B. A. and Baker, J. W. [2015] "Ground motion directionality in the 2010-2011 Canterbury earthquakes," Earthquake Engineering and Structural Dynamics, 44, 371-384. doi: 10.1002/eqe.2474

Cantagallo, C., Camata, G. and Spacone, E. [2012] "Demand of Reinforced Concrete Structures," Proc. of the 15th World Conference on Earthquake Engineering, Lisbon Portugal.

Carballo, J. E. [2000] "Probabilistic seismic demand analysis: spectrum matching and design," Reliability of Marine Structures Program Technical Report RMS-41. Stanford Digital Repository.

Carr, A. J. [2002] "Ruaumoko 2d y 3d Inelastic Dynamic Analysis Program [Software]," University of Canterbury, Christchurch, New Zealand.

Chen, W. and Atsuta, T. [1976] "Theory of Beam-Columns, Volume 1: In-Plane Behavior and Design,” McGraw-Hill, Inc., Nueva York, pp.513.

Chopra, A. K. and Chintanapakdee, C. [2001] "Comparing response of SDF systems to near-fault and far-fault earthquake motions in the context of spectral regions," Earthquake Engng Struct. Dyn., 30, 1769-1789. doi: 10.1002/eqe.92

Garcia-Soto, A. D., Hong, H. P. and Gómez, R. [2012] "Effect of the orientation of records on displacement ductility demand," Canadian Journal of Civil Engineering, 39(4), 362-373.

Diaz, S. A., Pujades, L.G., Barbat, A.H., Vargas, Y.F. and Hidalgo-Leiva, D.A. [2017] "Energy damage index based on capacity and response spectra," Eng Struct, 152, 424-36. doi: 10.1016/j.engstruct.2017.09.019.

FEMA 355C [2000] "State of the art report on system performance of steel moment frames subject to earthquake ground shaking," SAC Joint Venture Partnership for the Federal Emergency Management Agency, Washington. 
Fontara, I-K.M., Kostinakis, K.G., Manoukas, G.E. and Athanatopoulou, A.M. [2015] "Parameters affecting the seismic response of buildings under bi-directional excitation," Struct Eng Mech, 53(5):957-79.

Hancock, J., Watson-Lamprey, J. A., Abrahamson, N. A., Bommer, J. J., Markatis, A., McCoyh, E. and Mendis, R. [2006]"An Improved Method of Matching Response Spectra of Recorded Earthquake Ground Motion Using Wavelets," Journal of Earthquake Engineering, 10(1), 67-89. doi:

$10.1080 / 13632460609350629$

Ibarra, L. F., Medina, R. A. and Krawinkler, H. [2005] "Hysteretic models that incorporate strength and stiffness deterioration," Earthquake Engineering and Structural Dynamics, 34(12), 1489-1511. doi: 10.1002/eqe.495

Jayaram, N., Lin, T. and Baker, J. W. [2011] "A Computationally efficient groundmotion selection algorithm for matching a target response spectrum mean and variance," Earthquake Spectra, 27(3), 797-815. doi: 10.1193/1.3608002

Kostinakis, K. Morfidis, K. and Xenidis, H. [2015] "Damage response of multistorey r/c buildings with different structural systems subjected to seismic motion of arbitrary orientation”, Earthquake Engineering and Structural Dynamics, 44, 1919-1937.

Kostinakis, K. G., Manoukas, G. E., and Athanatopoulou, A. M. [2018] "Influence of seismic incident angle on response of symmetric in plan buildings," KSCE Journal of Civil Engineering, 22(2), 725-735. doi: 10.1007/s12205-017-1279-1

Krawinkler H [1978] "Shear in beam-column joints in seismic design of steel frames," Eng J, 15(3), 82-91

Lagaros, N. D. [2010] "The impact of the earthquake incident angle on the seismic loss estimation," Engineering Structures, 32(6), 1577-1589. doi:

10.1016/j.engstruct.2010.02.006

Lignos, D. G. and Krawinkler, H. [2011] "Deterioration Modeling of Steel Components in Support of Collapse Prediction of Steel Moment Frames under Earthquake Loading," Journal of Structural Engineering, 137(11), 1291-1302. doi: 10.1061/(ASCE)ST.1943-541X.0000376

Lignos, D. G. and Krawinkler, H. [2013] "Development and Utilization of Structural Component Databases for Performance-Based Earthquake Engineering," Journal of Structural Engineering, 139(8), 1382-1394. doi: 10.1061/(ASCE)ST.1943541X.0000646 
Lucchini, A., Monti, G. and Kunnath, S. [2011] "Nonlinear Response of Two-Way Asymmetric Single-Story Building under Biaxial Excitation," Journal of Structural Engineering, 137(1), 34-40. doi: 10.1061/(ASCE)ST.1943541X.0000266

Luzi, L., Pacor, F., and Puglia, R. [2017] "Italian Accelerometric Archive v 2.2. Istituto Nazionale di Geofisica e Vulcanologia," Dipartimento della Protezione Civile Nazionale. doi: 10.13127/ITACA.2.2

Mackie, K. R., Cronin, K. J. and Nielson, B. G. [2011] "Response Sensitivity of Highway Bridges to Randomly Orientes Multi-Component Earthquake Excitation," Journal of Earthquake Engineering, 15(6), 850-876. doi: $10.1080 / 13632469.2010 .551706$

Nguyen, V.T. and Kim, D. [2013] "Influence of incident angles of earthquakes on inelastic responses of asymmetric-plan structures," Structural Engineering and Mechanics, 45(3), 373-389.

Paz, M. and Leigh, W. [2004] "Structural Dynamics: Theory and Computation," Springer, United States. doi: 10.1007/978-1-4615-0481-8

Pinzón, L. A., Pujades, L. G., Diaz, S. A. and Alva, R. E. [2018a] "Do Directionality Effects Influence Expected Damage? A Case Study of the 2017 Central Mexico Earthquake," Bulletin of the Seismological Society of America, 108(5A), 25432555. doi: $10.1785 / 0120180049$

Pinzón, L. A., Pujades, L. G., Hidalgo, D. A. and Diaz, S. A. [2018b] "Directionality models from ground motions of Italy," Ingegneria Sismica, 35(3), 43-63.

Rigato, A. B. and Medina, R. A. [2007] "Influence of angle of incidence on seismic demands for inelastic single-storey structures subjected to bi-directional ground motions," Engineering Structures, 29(10), 2593-2601. doi: 10.1016/j.engstruct.2007.01.008

SAC [1996] "Analytical and field investigations of buildings affected by the Northridge earthquake," Report no. SAC-95-04, prepared by SAC Joint Venture, a partnership of SEAOC, ATC and CUREE.

Seifried, A. [2013] "Response spectrum compatibilization and its impact on structural response assessment," Ph.D. Thesis., Civil Engineering Dept., Stanford University, Stanford, California.

Shahi, S. K. and Baker, J. W. [2014] "NGA-West2 models for ground motion directionality," Earthquake Spectra, 30(3), 1285-1300. 
The MathWorks. [2017] "MATLAB and Statistics Toolbox Release 2016b," The MathWorks, Inc., Natick, Massachusetts, United States.

Torbol, M. and Shinozuka, M. [2014] "The directionality effect in the seismic risk assessment of highway networks," Structure and Infrastructure Engineering, 10(October), 175-188. doi: 10.1080/15732479.2012.716069

Vamvatsikos, D. and Allin Cornell, C. [2002] "Incremental dynamic analysis," Earthquake Engineering and Structural Dynamics, 31(3), 491-514. doi: 10.1002/eqe. 141

Vargas-Alzate, Y. F., Pujades, L. G., Barbat, A. H., Hurtado, E., Diaz, S. A. and Hidalgo-Leiva, D. A. [2018] "Probabilistic seismic damage assessment of reinforced concrete buildings considering direccionality effects," Structure and Infrastructure Engineering, 14(6), 817-829. doi: $10.1080 / 15732479.2017 .1385089$ 